\title{
BLACK AGENCY AND THE ONGOING STRUGGLE FOR BLACK EDUCATIONAL OPPORTUNITY
}

\author{
Carla O'Connor \\ School of Education, University of Michigan
}

CArla Shedd, Unequal City: Race, Schools, and Perceptions of Injustice, New York: Russell Sage Foundation, 2015, 244 Pages, ISBN 978-0-87154-796-5. \$35.00 paper.

Amanda E. Lewis and John B. Diamond, Despite the Best Intentions: How Racial Inequality Thrives in Good Schools, New York: Oxford University Press, 2015, 272 Pages, ISBN 978-0-19534-272-7. \$27.95 hardcover.

...theoretically, the Negro needs neither segregated schools nor mixed schools. What he needs is Education.

-W. E. B. Du Bois, "Does the Negro need separate schools?"

fournal of Negro Education (1935, p. 335)

...the real evil of pre-Brown public schools [is] the state-supported subordination of blacks in every aspect of the educational process. Racial separation is only the most obvious manifestation of this subordination. Providing unequal and inadequate school resources and excluding black parents from meaningful participation in school policymaking are at least as damaging to black children as enforced separation... Whether based on racial balance precedents or compensatory education theories, remedies that fail to attack all policies of racial subordination almost guarantee that the basic evil of segregated schools will survive and flourish, even in those systems where racially balanced schools can be achieved. Low academic performance and large numbers of disciplinary and expulsion cases are only two of the predictable outcomes in integrated schools where the racial subordination of blacks is reasserted in, if anything, a more damaging form.

—Derrick Bell, "Serving Two Masters: Integration Ideals and Client

Interests in School Desegregation Litigation," The Yale Law Fournal

(1976, pp. 487-488)

Du Bois Review, 13:2 (2016) 413-424.

(C) 2016 Hutchins Center for African and African American Research 1742-058X/16 \$15.00

doi:10.1017/S1742058X16000254 
Forty-one years separated W. E. B. Du Bois's and Derrick Bell's shared recognition that school desegregation would not resolve the struggle for Black educational opportunity. Du Bois pronounced, "...I am no fool...I know that race prejudice in the United States today is such that most Negroes cannot receive proper education in white institutions" (1935, pp. 328-329). Writing nearly twenty years before the Brown v. Board of Education decision, Du Bois's (1935) concern with "race prejudice" was focused on its more vulgar expression as demonstrated by White "animosity" (p. 328). He explained that Blacks may have been "admitted and tolerated" in White (Northern) schools but "not educated" nor "welcomed" (p. 329). There they received neither "decent" nor "sympathetic" education and found themselves "despised," "resented," "neglected and bullied" (Du Bois 1935, pp. 329-330). Du Bois indicated that the harm to Black children was not limited to what they learned or failed to learn academically but what they came to understand about themselves, their positioning, their history, and their agency as Black subjects.

Approximately twenty years after the Brown decision, Derrick Bell (1976), emphasized that the durability and insidiousness of race prejudice is most powerfully articulated via state-supported black subordination. Rather than highlight the abject neglect and palatable disdain Black children experienced in their encounters with White children, parents, and teachers in desegregated schools, he drew our attention to race prejudice (or more precisely racism) that is evidenced via institutionalized policies and systematic practices that are more nuanced and less perceptible (or obvious) but are no less profound and debilitating than state sanctioned school segregation. Although Bell did not explicitly indicate, as Du Bois had, that the impact on Black children extended beyond readily measured educational outcomes (as per his reference to academic performance and disciplinary and expulsion rates), he did indicate that institutionalized racial subordination reasserts itself in new forms that produce a range of predictable and, by implication, less predictable outcomes.

Having published their books in 2015, Carla Shedd, author of Unequal City: Race, Schools, and Perceptions of Injustice, and Amanda E. Lewis and John B. Diamond, authors of Despite the Best Intentions: How Racial Inequality Thrives in Good Schools differentially take up, refine, expand upon, and resituate the concerns raised by Du Bois and Bell. Both books, using Chicago as the field setting, are concerned with the ongoing struggle for Black educational opportunity; how that struggle seems to be indeterminably tied to the racial demographics of schools, and how in the pursuit of educational opportunity Blacks must still cross the racial (and by implication class and resource) boundaries that distinguish schools. In the process they confront new forms of institutionalized racial subordination.

In unpacking these new forms of racial subordination, Shedd and Lewis and Diamond make evident the paradoxes that emerge when, in this contemporary era, many Black students and their families still find themselves "choosing" between segregated and desegregated schools rather than choosing an education that guarantees their ability to thrive academically, psychologically, and socio-culturally. Below I elaborate a bit more on this choice context as evidenced by these texts and then discuss in detail the findings and contributions of each book as well as a key lingering question for both texts: Where is the promise for Black collective and political agency in the ongoing struggle for Black educational opportunity?

\section{THE “CHOICE” CONTEXT(S)}

Although the majority of Black and Brown children in Chicago (and in other urban centers) remain sequestered in racially segregated and underresourced schools, some 
Black and Brown children do have the "choice" to attend more resourced and racially integrated schools. The gains of the Civil Rights Movement have enabled some Blacks (particularly the middle class) to activate school choice by moving into neighborhoods featuring these presumably "good" schools; and the proliferation of charter schools and the expansion of open enrollment policies in Chicago and elsewhere have otherwise enabled Black children and their families to choose these "good" schools over their neighborhood schools.

Lewis and Diamond illuminate the first choice context by documenting how Black children experience Riverview High School, their racially integrated and wellresourced neighborhood high school, located on the north side of Chicago. Shedd contends with the second choice context and documents the experiences of Black children who leave their south side neighborhoods each day to attend either Lincoln Park High School or Walter Payton Preparatory High School, two selective, racially diverse, and highly resourced schools. Both schools, like Riverview, are located on the north side of Chicago. Shedd compares how the experiences of Lincoln Park and Payton students compare with those of children who also reside on Chicago's south side, but attend either Harper High School or Tilden Career Community Academy High School, two racially segregated and underresourced high schools within a short distance from their homes. While Lewis and Diamond are singularly and substantively focused on how institutionalized Black subordination is articulated every day through the micro-interactions and micro-political processes that animate, and are animated by, school policies and practices, Shedd emphasizes how Black (and Brown) subordination is experienced in the journey between home and school and is especially influenced by the penal character of both urban streets and urban schools. Lewis and Diamond explore the relationship between their documentation of "everyday" Black subordination and Black achievement. Shedd, advancing what she refers to as a "placesensitive" sociology, primarily concerns herself with how the journey between home and school, and the subordinating experiences embedded therein, "expand" (or not) youths' contexts for making sense of injustice.

\section{JOURNEYING TO OPPORTUNITY OR THE CONSTRUCTION AND REINFORCEMENT OF INJUSTICE?}

According to Shedd, a "place-sensitive" sociology appreciates place "not just as a backdrop to our social lives but also as an agentic player in our lives with measureable and independent effects" (p. 8). Inspired by literature on neighborhood effects, Shedd demonstrates this sensitivity by establishing Chicago as an "unequal city" that is ripe for exploring "how race and place shape youth perceptions of social and criminal injustice" (p. 157). She begins by documenting how racial and socio-economic segregation in Chicago-itself a product of histories of racism and structured inequalityintersect with housing and especially school reform policies to produce "a racially ordered 'geography of opportunity' wherein the resources for improving school and life chances are meted out by race, class, and zip code" (p. 28). More specifically, Shedd orients the reader to how the Illinois Charter School Law of 1996 (which authorized charter schools) and The Renaissance 2010 Plan of 2004 (which was designed to replace underperforming neighborhood schools with instructionally innovative schools) extended the promise of greater educational opportunity for those willing to transgress local school attendance boundaries.

Shedd indicates that this reconfiguration of educational opportunity coincided with the razing of Chicago's largest public housing projects and the relocation of 
their residents. By implication, the Black youths among them were displaced not only from their "residential" but their "educational" communities. Taken together, these housing and school reform policies meant that many Chicago adolescents were now traveling longer distances-geographically, psychologically, and symbolically-to attend schools that promised them greater educational and social opportunity. Significantly, their passages were not safe because these policies emerged against an upsurge in Chicago violent crime which was met with increased policing that eventually seeped into school policies and practices. Shedd notes, "...police officers and other mechanisms of social control have become a central feature of urban schools since the early 1990s, in tandem with the peak in violent crime in large urban cities in the nation" (p. 19).

Shedd is ultimately concerned with how youths', but especially how black youths', "perceptions of themselves and the larger social world are shaped by their daily interactions with others" in their journey back and forth from home to school-particularly if that journey carries them into Whiter and wealthier neighborhoods and, by implication, into more racially diverse and highly resourced schools (p. 3). Of particular concern are the "symbolic and actual dangers" youths must make sense of and navigate (e.g., differential surveillance and monitoring in school and public settings; contact with police in and out of school; transgression of gang boundaries). According to Shedd, such sense-making and navigation teaches youths important lessons about the "boundaries of race, place, class and more and how to achieve safe passage within and across these boundaries" (p. 159). In order to capture these lessons, Shedd relies on both survey and interview data.

The survey data, collected by the Chicago Consortium on School Research (CCSR), captures, among other things, how some 20,000 ninth- and tenth-grade students enrolled in Chicago Public Schools, perceive of social injustice (i.e., "whether racial discrimination makes it difficult for members of his or her race to "find a job" and "find a place to live"”) as well as criminal injustice (i.e., assessments of "various forms of discrimination and measures... of whether or not police engage in racial, gender, age, and class discrimination") (Shedd 2015, p. 168). These survey data were supplemented by initial (and when feasible, five-year follow up) open-ended interviews with forty teenagers, who also completed a replication of the CCSR survey. These students were equally distributed across the four aforementioned schools that differed on the basis of racial composition, selective enrollment, and their surrounding neighborhoods; and the ten students from each school were selected with the goal of maximizing "the variation of respondents by racial composition, perceptions of social and criminal justice, and police contact" (p. 169). In interviewing them, Shedd sought to make sense of "everything from how they traveled to school to which class they enjoyed best, how much their parents supervised their free time, and even their ideas about the rules and laws they had to follow inside and outside the schoolhouse doors" (p. 169).

The intent of Shedd's study is novel and compelling and the design is both promising and intriguing with regards to considering the school journeys of adolescents attending schools that differ in terms of demographics and opportunity. Shedd convincingly argues that if we want to understand how youths make sense of social and criminal injustice it is not enough to examine their interactions with courts, jails, and the criminal justice system; we must examine far more mundane enterprises including their travel back and forth to school and the interactions that are embedded thereinincluding their interactions with same and different race peers and adults, and their interactions with the police and their concomitant sense of safety. She notes that we must also examine their experiences in school with particular attention to how they make sense of the shadow carceral system that has become a common feature of urban schools. Shedd shows that this system is more physically salient in under-resourced 
and racially isolated schools (via the presence of metal detectors and police in and around school campuses) and more symbolically salient in highly resourced and racially diverse schools (via the heightened surveillance and disproportionate punishment of Black and Brown youths compared to White youths). Shedd also captures the imagination and investment of the reader when she notes that her work will complicate current discourse regarding neighborhood effects which has inadvertently marginalized how (traveling to) schools effect students' experiences and perceptions. Unfortunately, Shedd's findings, interpretation, and articulation of the study's implications are less compelling than they might have been given the intrigue raised by the objectives and design of her study.

Shedd's survey and interview data show that African Americans and Hispanics "who travel farther along the racial-spatial divide" to "attend more racially integrated (and better resourced) schools," have "'expanded contexts' or wider frames of comparison, than their peers who travel shorter distances" and attend majority Black or Hispanic schools (p. 140). These long distance travelers are much more sensitized to injustice, particularly if their school neighborhood contexts are "dissimilar on several measures of significance-racial composition, quality of resources, policing tactics, and so on" (p. 140). Shedd elaborates that the isolation of students attending south side schools not only sequesters them "from job opportunities and housing choices, to name a few" but from "unequivocal evidence that they are likely to receive inferior treatment because of their race" (p. 62). Shedd explains that although young people "are likely to recognize [old-fashioned discrimination and prejudice] even when they live in and attend school in racially homogenous socially isolated neighborhood [like those on the south side of Chicago], their perception of structural discrimination is more uneven" (p. 72). It is uneven because, absent an expanded or comparative frame, they are limited in their ability to robustly and profoundly assess their group's relative disadvantage. Thus while race still predicted perceptions of social and criminal injustice with Black and Hispanic students perceiving greater injustice than Asian or White students, the within group variation with which Black and Hispanic students made sense of injustice was a function of whether they attended segregated, resource poor versus racially diverse, resource rich schools.

Nowhere was the effect of schools more salient than in explaining how students made sense of criminal injustice. This was especially the case for those Black and Brown students who attended school on the north side and had a high perception of criminal injustice despite having had no personal contact with the police. How did these students "come to believe that members of their race are more likely to be "treated worse' and 'stopped and/or searched by the police"' (p. 104) when they, compared to many of their peers attending south side schools, did not report having been stopped, searched, or told to move on by police? After all, Shedd collected her data prior to the dawning of the Black Lives Matter movement and the relentless public discussions about the susceptibility of Black people to criminal injustice. Shedd explains that it was the carceral apparatus in schools (even if more subtly articulated in north side schools) that helps to explain this quandary. She notes that in the absence of police contact outside of schools, her participants' "perceptions of injustice have been shaped by their experiences, both personal and vicarious, with police and security guards in their school environments" (p. 118, author's emphasis) which included being subject to differential enforcement of school rules and codes of conduct on the part of these and other schools officials (e.g., teachers) or witnessing such differential treatment along racial lines.

Early on in her book Shedd asks, "What exactly are our young people learning in school—not just about math and science but also about their own importance and 
the relative worth of their peers?" (p. 18)—a question anticipated by Du Bois. In her book she makes evident that if they are Black and Brown and they leave their Black and Brown neighborhoods to pursue educational opportunity a great distance from their homes, their journey to and experience in these Whiter and wealthier schools confirms their group's structured disadvantage and their vulnerability to the criminal gaze.

Shedd offers important and robust claims and establishes a significant empirical case regarding the unanticipated consequences of journeying to opportunity and experiencing subordination along the journey and upon arrival at the destination. However, her presentation and interpretation of the qualitative data (meant to animate and elaborate upon the quantitative data) is less cogent than it might have been. Given the small number of student participants who varied in terms of race, ethnicity, and socio-economic status and stretched across four school contexts, Shedd often struggled in her effort to report on the broad territory of experience and perspectives that coincided with this variation and then stitch these varied experiences and perspectives together in a manner that convincingly accounted for prominent themes and claims. As such, the prospective promise and power of Shedd's qualitative data and the extent to which they added texture to the quantitative findings is not fully realized. This is not the case for Despite the Best Intentions which compellingly integrates quantitative and qualitative data to evidence and theorize how the evil of Black subordination is reasserted in new forms in racially diverse schools.

\section{THE EVERYDAY INSTANTIATION OF INSTITUTIONALIZED RACISM AND WHITE SUPREMACY IN SCHOOL ROUTINES}

In their book, Lewis and Diamond examine the ostensibly race-neutral policies and practices that are inevitably animated by race-central micro-interactions and micropolitical processes to produce, sustain and justify racial gaps in educational outcomes. Their book project builds upon growing interest in better understanding how schoolbased processes contribute to achievement gaps, especially in light of continued evidence that socioeconomic background and family resources, while very influential, do not explain these gaps in full. Lewis and Diamond also deliberately and effectively tangle with the most prominent explanation for the Black-White gap in particular: the oppositional culture argument or the notion that Black students expend limited effort in school because of the negative influences of a Black peer culture that defines schooling as a White domain and as an enterprise that fails to yield comparable rewards for Blacks and Whites.

Like Shedd, Lewis and Diamond rely on both quantitative and qualitative data. They similarly had the opportunity to take advantage of a secondary data set-in their case, the Assessment of Secondary School Student Culture that was administered at Riverview and fourteen similar districts and captured the perspectives and experiences of 25,000 seventh- to eleventh-grade students with regards to the following: academic achievement, academic behaviors, experience with negative peer pressure, affect toward school, academic aspirations, and friend group racial composition. Lewis and Diamond also rely on interviews with a racially and ethnically diverse group of participants; but in addition to interviewing Black, White, and Latino students (eightythree in total), they had the benefit of interviewing many of these students' parents and also teachers and staff across various departments and units at Riverview. Students were asked to discuss their school experience, educational aspirations and expectations, perceptions of race and opportunity, and beliefs about the relationship between peer dynamics and school achievement. Among other things, the adults were asked to 
discuss how they experienced Riverview (including its policies and practices), how they made sense of racial achievement gaps, and how their children (in the case of parents) and students of different racial groups experienced Riverview.

Before getting to the heart of their findings and the substance of their theorization, Lewis and Diamond deliberately work to debunk the oppositional culture argument. Towards this end, in chapter two they recount current evidence (both survey research and ethnographic) that indicates that key assumptions of the argument are broadly unsubstantiated for Black youths and their families. They, however, acknowledge that there is, nevertheless, some evidence that oppositional culture may have traction in racially integrated schools, like Riverview. For this reason, they empirically explored "whether there is a culture of opposition among Black students at Riverview" and found "that there is virtually no support for the oppositional culture argument in [their] data" (pp. 21, 22). More specifically, in conflict with the logic and suppositions of the oppositional culture argument, their data indicate (among other findings) that: (1) despite being sensitized to racial discrimination and an inequitable opportunity structure (often via familial influences and their own experiences in school), Black students demonstrated more pro-school attitudes than their White peers and remained committed to the notion that education paid off and could be a resource in combatting the racism they anticipated; (2) Black students were no more likely than White students to experience negative peer pressure for achievement and, like White students, those who reported experiencing teasing for high achievement were a minority $(20 \%$ or less); and (3) Black students reported receiving more academic support and encouragement from their friends than was the case for White students.

A couple of conundrums were, however, raised by their quantitative data analysis, including the finding that, compared to their White counterparts, Black students reported being less happy at school. Lewis and Diamond indicate that "given that black students don't report negative feelings about specific school activities, it is very likely that black students' lower levels of reported happiness at their schools is likely dissatisfaction with the education institutions themselves rather than opposition to the actual educative process" (p. 43). This speculation establishes an important prelude to their subsequent reporting of how Black (versus White) students and their families experience Riverview's disciplinary and tracking routines-and why a focus on these and other schooling processes provide a more profitable starting point for understanding racial patterns in educational outcomes compared to our previous focus on the culture (and by implication pathology) of Black folks.

Using organizational theory, racialization theory, and theories of capital and reproduction as key interpretative frames, Lewis and Diamond document how Riverview's disciplinary and track placement routines function as everyday institutionalized racism. They explain that the school's rules and placement procedures appear rational in and of themselves and equally applicable to all students (what Lewis and Diamond categorize as the ostensive aspect of routines). However, these routines are enacted in ways (i.e., the performative aspect of routines) that systematically disenfranchise Black and Brown students and privilege White students. According to Lewis and Diamond, such inequity emerges because the school officials enacting the routines are not only susceptible to implicit biases and unconscious racism but are deferential to the power and status of White families. These orientations on the part of school officials, and the subsequent impact on how routines are performed, make evident how "race works structurally (affecting who has access to certain kinds of resources)" as well as "symbolically (affecting how we understand who is around us)" (p. 49).

Lewis and Diamond show that as per the symbolic operation of race in Riverview, Black students are more apt to be selected for punishment because of pervasive racial 
stereotypes about the criminality of Black people (and also the hypersexuality of Black girls). They are also less likely to be enrolled in more selective courses (i.e., honors and advancement placement courses) because of stereotypes that mark them as less academically competent or inclined and the subsequent extension of lower performance expectations. In contrast, pervasive assumptions about the innocence of Whites (including the perceived sexual innocence of White girls) allow them to elude scrutiny and surveillance and to decrease, in turn, the likelihood that they will be observed or interpreted as having transgressed school rules, dress codes, or codes of conductthereby diminishing their chances of being selected for punishment. With regards to track placement, pervasive positive assumptions regarding Whites' academic ability and inclination, unreflexively orient school officials to high performance expectations and to recommend or facilitate, in turn, White students' enrollment in more rigorous courses.

At the structural level, racism, as it has been articulated across time, has led to the confounding of race and class such that, on average, Whites evidence more elite economic and educational statuses and more dominant cultural know-how than Blacks. They then leverage these statuses and know-how to manipulate school routines to the advantage of their children. This common place navigation and negotiation of routines on the part of many socio-economically advantaged White parents not only results in their own children receiving favorable processing in both the disciplinary and tracking systems, but accords advantage to White children as a whole. More specifically, Lewis and Diamond elucidate how the anticipation that White parents with power will resist both negative disciplinary decisions and lower track placement, inclines school officials to unreflexively process almost any White student more favorably in the disciplinary and tracking systems. This anticipatory response thereby converts the economic and cultural capital of some Whites into symbolic capital for all Whites. That is, being White comes to symbolize statuses and orientations that trigger and institutionalize White preferential treatment in the enactment of school routines.

What is especially compelling about Lewis' and Diamond's analysis is their ability to show that the power and durability of these raced micro-assessments, -actions, and -interactions are a function of their subtlety. These micro-processes, which constitute "everyday racism," in no way approach the kind of vitriolic or intentional racism to which Du Bois alluded. Rather, to quote Beverly Tatum (2001), this articulation of racism operates like "smog in the air" (p. 125). The smog constitutes "the images and messages that affirm the assumed superiority of whites and the assumed inferiority of people of color" (Tatum 2001, p. 125). Tatum notes that, like smog, these images and messages are sometimes thick enough to be visible but are often imperceptible; and that, regardless of their perceptibility, we breathe in and are influenced by these images and messages each day. As per Lewis' and Diamond's analysis, then, we should not be concerned with whether individual school officials or parents are racist but how this smog unreflexively informs the meaning-making of even well intended practitioners and parents to affect how their response to and take up of school practices and policies produces racial patterns in educational outcomes.

Lewis and Diamond subsequently theorize how these raced and stereotype laden policies and practices are then institutionally reinforced and legitimized via the opportunity boarding of Whites. They make clear that the White families at Riverview "are not focused on directly blocking racial minorities as they are focused on securing advantage for their own" (p. 156), and in the process of securing this advantage they "advocate... for the maintenance of the structures of inequality that facilitate their advantage" (p. 156). As such, Lewis and Diamond document the pressure school personnel "felt from middle-class white parents not to change anything about the tracking system or any of the related practices that currently created and/or reinforced white students' 
advantages" (p. 135). "Believing that there were not enough resources to do everything well, these parents... [sought] to ensure that their children continue[d] to get the best of what Riverview ha[d] to offer" (p. 138). Even in instances where White parents were willing to support supplementary programs aimed at closing racial achievement gaps (rather than overhaul the system to facilitate racial equity), school officials reported that these programs "eventually became populated by white students" if they were shown to produce "positive results" (p. 139).

Having actively facilitated and reinforced their children's advantaged status in the academic hierarchy, Lewis and Diamond show how White parents subsequently rationalized the racial stratification of this hierarchy via the invocation of racial stereotypes and status beliefs. That is, breathing in the smog yet again, White parents were shown to attribute Blacks' disadvantaged status in the academic hierarchy to cultural deviance and deficiencies on the part of Black children and Black families. By implication they distinguished themselves and other White families as normative and as culturally superior. According to Lewis and Diamond:

How do members of the white middle and upper class rationalize their positions in status hierarchies? They engage in ideological work, including the marking of symbolic boundaries between deserving and undeserving social actors, or people "above" and "below" others. A key mechanism is the creation of symbolic boundaries using ideas drawn from a larger social milieu. (p. 152)

Other scholars have previously documented the extent to which Black and Brown students are susceptible to the criminal gaze and pejorative assumptions regarding their sexual, academic, and cultural inclinations. Lewis and Diamond, however, accomplish two significant analytical feats having also documented the same. Their analysis makes evident how such meaning-making, "despite the best intentions," gets instantiated in the micro-level enactments of educational policy and practice to produce and rationalize racial hierarchies in schools. Additionally, their analysis is not limited to the ways Black students and their parents experience this subordination, but how White supremacy gets institutionalized and rationalized as per "the key role white actors play and have always played in reproducing their own racial advantage" (p. 154). They thus make empirically and theoretically transparent how Black subordination and White supremacy are inextricably yoked.

\section{UNRESOLVED DILEMMAS IN THE PURSUIT OF EDUCATIONAL OPPORTUNITY}

Both Unequal City and Despite the Best Intentions reveal what Carla Shedd coins as the "paradoxes of progress." In a city where there is a clear "geography of opportunity" some Black students and their families have traversed this geography to find themselves in "good" schools. These better resourced (and therefore Whiter and wealthier) schools evidence better facilities, more experienced teachers, and more rigorous curriculum and instruction. The problem is that we are now more than sixty years past the Brown v. Board of Education decision-what was then imagined as a decisive blow against Black educational subordination-and, paradoxically, it is still the case that these presumably good schools are not yet good for Black and Brown children.

For some (like the Black and Brown students in Shedd's study) the goodness is compromised by the inherent indignity of having to rise early and travel far outside of your neighborhood to have access to the quality educational resources that most White, 


\section{Carla O'Connor}

middle class children experience within a short distance of their homes. But once inside these schools (whether as function of an arduous journey or because youths are among a Black minority that resides in communities that feature such schools), Black students find that these schools are culturally, socially, and institutionally organized in ways that amplify and reify their subordination. These new forms of subordination evidence greater subtlety and have often escaped sufficient public scrutiny because they are instantiated in routine schooling practices that are either: (1) represented as equitable and racially neutral (as demonstrated by Lewis and Diamond); or (2) advanced in the interest of some greater good like school or public safety (as demonstrated by Shedd). Their everydayness, subtlety, and nods to equity and safety make them that much more intractable because it is less than clear how to galvanize robust opposition to them as was the case when Blacks collectively resisted more obvious forms of Black subordination (e.g., de jure school segregation). As such, the following is the unspoken dilemma in each text: What is the prospect for Black human and political agency in the contemporary battle for Black educational opportunity (and ideally liberation)?

In the case of Unequal City that which might plant the seeds for such agency is positioned as a liability. Shedd indicates, "The fact that increased school diversity may lead to higher perceptions of injustice among African American and Hispanic youth speaks to the 'protective' properties of segregation and social isolation, which can prevent youth from confirming their individual- and group- level disadvantage" (p. 160). When we place this assessment within the context of Shedd having previously noted that "perceptions of social injustice are positively related to crime and delinquency" (p. 12) it is clear that Shedd struggles to conceive of how the recognition of injustice can function as a political resource. Shedd does signal that it can function as a psychological resource when she notes how this recognition can protect Black and Brown people from self-blame. Namely, she indicates:

When youth whose lives are governed by unjust institutions fail to perceive injustice, but also fail to succeed, they understand their failure to be personal instead of perceiving race, class, or other social factors as key contributors to social inequality (p. 160).

However, she inadvertently converts the recognition of injustice into a substantive impairment in encounters with the state. She notes:

Individuals who perceive low levels of injustice may believe that members of their group are treated as fairly as other groups, or even better because they truly are (the case with the White and Asian American or Filipino students in the sample), or because they have a "restricted comparative frame" or reduced expectations (the experience of youth who live and learn in the same neighborhood in a low-resource environment). The ninth-grader attending Harper who has been searched but not arrested multiple times in one year may simply assume that this happens to everyone (p. 161).

Shedd then asks: "What will happen to him when he realizes that this is not in fact the case?" (p. 161). Her answer (absent additional elaboration): "The consequences of this dawning realization must be addressed, especially since police contacts are the most direct link between law enforcement and the public" (p. 161). This answer, however imprecise, suggests only negative consequences and portends dangerous outcomes as per the state apparatus that is of central interest in this book (i.e., the police and criminal justice system). 
What is lost from consideration is how such dawnings might also facilitate and embolden social movements or protest activity. The Black Lives Matter movement is one contemporary manifestation of being "woke" in this way. But there is also historical evidence that under the right resource, political, strategic, and organizational conditions the anger and moral outrage spawned by the recognition of injustice can be converted into protest movements and rebellious activity that facilitate or are oriented towards social change (Brush 1996; Giugni 1998; Tyler and Smith, 1995). Driven sometimes and in part by a sense of relative deprivation (a concept that is central to Shedd's analysis and undergirds her considerations regarding perceptions of injustice), it is often the more advantaged members of disadvantaged groups who have been shown to engage in collective action because they are well positioned to draw upon the very comparative frames to which Shedd wants the reader to attend (Caplan and Paige, 1968; Gurin and Epps, 1975; Tyler and Smith, 2001). As such, the south side students who are attending Payton and Lincoln Park, and who have a heightened recognition of injustice as per their more privileged educational access, may actually be well poised to inspire and engage in collective action aimed at combatting Black subordination. And even the prospective conflict with police to which Shedd insinuates as per these dawnings may do other than compromise and endanger Black bodies. As evidenced by the Black Lives Matter movement, these conflicts might spawn more coordinated collective work aimed at facilitating social change and Black (educational) liberation.

In the case of Lewis and Diamond, that which is especially powerful about their work (i.e., the documentation and theorization of how White agency operates nimbly and powerfully to sustain racial hierarchies via its structural and symbolic animation of school routines), inadvertently diminishes the prospects that Blacks might effectively tangle with White agents who are always and already more materially and symbolically powerful than Black and Brown agents and can thus puppeteer and perpetuate raced educational inequities to their advantage. In Despite the Best Intentions the seeming limits of Black agency are also evidenced by the fact that the Black parents, and especially the Black school officials, who report on and often express frustration with the racially unjust routines, are positioned as a poor match for the socio-economically privileged Whites who want to sustain the systems "as is." It is not that Lewis and Diamond fail to recognize the importance of cultivating and enacting Black agency. In fact, citing Welner and Burris (2006), they note:

...[T] hose who have been on the losing end of tracking may not be as politically powerful as other constituencies, but their voices still need to be heard. "When parents of low-track students are politically invisible, they are too easily ignored" (Lewis and Diamond, 2015, p. 177).

And as per Lewis's and Diamond's findings, the same might be said for those who have been on the losing end of disciplinary systems. Lewis and Diamond take their recognition of the power of political agency one step further when they note that they "agree with Bonilla-Silva (2006) that what is needed to address the core [findings of their text] is a new "civil rights movements demanding equality of results"' (p. 180). This call for a new movement is consistent with their policy recommendation that what is warranted as per their findings is a "focus on disparate impacts rather than intentional discrimination" which requires institutions to not only collect disaggregated racial data but, moreover, conduct forensics on routines (or to use their words, unpack them "piece by piece") to determine "the actual sources of the discrepancies" and to then "modify the routine[s] accordingly" (p. 170). But their compelling articulation of the complex and slippery ways in which "structural inequalities, institutional 
practices, and racial ideologies mutually reinforce each other and collectively generate different educational trajectories" (p. 167) over and against the insights, frustration, and desire of Black folks makes it difficult to imagine how and from where Black insurgency might arise to support such a movement.

As per Du Bois, what Blacks still need is an education. They do not need segregated nor integrated schools, but schools that ensure their ability to thrive academically, psychologically, and socio-culturally. The Black Civil Rights Movement of the 1950s and 1960s, however, emphasized school desegregation over a fundamental attack on "all [educational] policies of racial subordination" (Bell 1976, p. 488). The basic evil of segregated schools has thus survived and flourished and, as is demonstrated by Shedd and Lewis and Diamond, has been reasserted in new and damaging forms in racially integrated schools (Bell 1976). At the same time, most Black children today attend majority minority schools where they are systematically denied high quality educational resources. The issue which arises is from where will the U.S. public generate the will and commitment to move decisively against both these reassertions and the enduring expression of separate and unequal educational systems. And what role will Black folks play in inciting this will and commitment? The work of Shedd and Lewis and Diamond inadvertently raise this question. In response, researchers need to document and analyze the power and agency that exists among Black folk and the prospect of them spawning in this contemporary era a new Civil Rights Movement that attacks all policies of racial subordination. The concomitant challenge is for researchers to explore whether and how schools might be a resource in, rather than an impediment to, the cultivation or articulation of not only Black (and Brown) agency but the agency of other racial subjects who will function as allies towards this end.

Corresponding author: Carla O'Connor, University of Michigan, School of Education, 610 E. University Avenue, 4001SEB, Ann Arbor, MI 48109-1259. E-mail: coconnor@umich.edu.

\section{REFERENCES}

Bell, Derrick A., Jr. (1976). Serving Two Masters: Integration Ideals and Client Interests in School Desegregation Litigation. The Yale Law fournal, 85(4): 470-516.

Bonilla-Silva, Eduardo (2006). Racism Without Racists: Color-Blind Racism in the Post-Civil Rights Era. Boulder, CO: Lynne Riener.

Brush, Stephen G. (1996). Dynamics of Theory Change in the Social Sciences: Relative Deprivation and Collective Violence. Fournal of Conflict Resolution, 40(4): 523-545.

Caplan, Nathan S., and Jeffery M. Paige (1968). A Study of Ghetto Rioters. Scientific American, 219: $15-21$.

Du Bois, W. E. B. (1935). Does the Negro Need Separate Schools? Fournal of Negro Education, 4(3): 328-335.

Giugni, Marco G. (1998). Was it Worth the Effort?: The Outcomes and Consequences of Social Movements. Annual Review of Sociology, 24: 371-393.

Gurin, Patricia, and Edgar Epps (1975). Black Consciousness, Identity, and Achievement: A Study of Students in Historically Black Colleges. New York: Wiley.

Tatum, Beverley D. (2001). Defining Racism: "Can we Talk?" In Paula S. Rothenberg (Ed.), Race, Class, and Gender in the United States: An Integrated Study, pp. 100-107. New York: Worth Publishers.

Tyler, Tom R. (2001). Social Justice. In Rupert Brown and Sam Gaertner (Eds.) Handbook of Social Psychology: Intergroup Processes, pp. 344-364. Malden, MA: Blackwell Publishers, Ltd.

Tyler, Tom R., and Heather J. Smith (1995). Social Justice and Social Movements. IRLE Working Paper No. 61-95. <http://irle.berkeley.edu/workingpapers/61-95.pdf> (accessed October 3, 2016).

Wellner, Kevin, and Carol Corbett Burris (2006). Alternative Approaches to the Politics of Detracking. Theory Into Practice, 45(1): 90-99. 